\section{MUSEUM METHODS.}

ON THE ARRANGEMENT OF GREAT PALEONTOLOGICAL COLLECTIONS.

A museum is defined by Dr. Goode as " an institution for the preservation of those objects which best illustrate the phenomena of nature and the works of man, and utilization of these for the increase of knowledge and for the culture and enlightenment of the people." *

The fundamental principles or aims of a museum having been defined, it is necessary to consider next in what manner collections of fossils may be arranged to fulfill these objects. The primary purposes are manifestly two: namely, to interest and instruct the general public, and to facilitate the researches of the student of extinct life. The latter class of museum visitors is composed of two kinds: namely, faunal geologists, or students of historical geology, and paleobiologists, or students of general biological phenomena.

"It is necessary to bear in mind," writes Sir Henry Howorth, "that it is a mistake to deal with mineralogy and paleontology as if they were sub-sections of geology," since " the great bulk of paleontological remains do not appertain to geology at all, but to the special provinces of zoölogy and botany." $\dagger$ This principle has long been accepted in the U. S. National Museum, and for many years the paleontological collections have been completely severed from the geological collections. In the Department of Geology there is, however, a small collection of fossils with samples of the rocks in which they are found, in order that the student of geology may learn to know readily the characteristic fossils of each system

*The Relationship and Responsibilities of Museums, by G. Brown Goode. (Science, Vol. II, new ser., p. 198, Aug., 1895.)

†Some Casual Thoughts on Museums, by Sir Henry Howorth. (Natural Science, Vol. VII., p. 322, Nov., 1895.) and the time of introduction of all the leading types of animals and plants. This collection is at present made up of American fossils, but it is intended to obtain from every province all specimens necessary to illustrate the second object of this, the ' Historical Collection.'

\section{THE GENERAL PUBLIC.}

This is the largest class of museum visitors, but the one least interested directly, so it need be shown only a series of specimens properly prepared for exhibition. "A museum is rarely justified in exhibiting all its materials. An exhibition series, when properly installed, is more effective when limited than when extensive." * To interest the public the exhibition series should be mounted in an attractive manner and made intelligible by descriptive labels. Only good and well-cleaned fossils, yet not too many species, should be shown, since otherwise a rapid survey of the specimens grouped around the descriptive labels is not attainable. Drawings or prints should, when possible, accompany small fossils, and occasionally a crushed specimen may be made comprehensible by introducing a restoration or the shells of living, but closely related forms.

STUDENTS.

On the other hand, students and original investigators must have consideration of a quite different kind. Since this small but critical class of museum visitors has objects distinct from those of the general public, it will be necessary to arrange collections so as to satisfy the needs of both. The general public should be interested and instructed, while the student requires an orderly arrangement of material to facilitate ready reference.

An exhibition series is primarily intended

* Recent adrance in Museum Method, by G. Brown Goode. (Smithsonian Report. U. S. National Museum, p. 57, 1893.) 
for the general public and the student, and consequently should be divided into stratigraphic and synoptic collections. The investigator may advantageously make use of both of these series, but will have additional aid in the study collections and the eard catalogues.

In recent years there has been a decided tendency to group all fossils according to their biological rank. This is proper if the chief object of a museum is to teach paleobotany and paleozoölogy. In large museums, however, it is necessary to teach not only everything pertaining to morphology, but the sequence of faunas, or historical geology, as well. Plants and animals do not occur in nature grouped according to their biological rank, but are associated because of their environment and geological history. If the great bulk of fossils is arranged biologically then the grouping and interactions of the individuals of a province or zone are apt to be lost sight of. Paleontologists seeking for the relationship which the various provinces bear to another, or the presence or absence of barriers against the dispersal of floras and faunas, will be seriously embarrassed by any arrangement other than stratigraphic. The dual evolution of the horse, or of the Terebratellidæ among the Brachiopoda, are problems both of the faunal geologist and of the systematic zoölogist as well:

A stratigraphic exhibition collection aims to show only the essential animals and plants of various well-marked geological horizons, and these systematically arranged, both geologieally and biologically. It should be sufficiently extensive to illustrate clearly Historical Geology, or the order of distribution of fossil remains throughout geologic time.

It is seemingly neither proper nor advisable to note all the minor geological horizons in large stratigraphic collections like those of the National Museum. For a clear demonstration of the facts of faunal geology, it is sufficient to group all the organisms of the Cambrian system into three divisions, representing the Lower, Middle and Upper Cambrian, respectively. The Ordovician system, in like manner, should be separated into Calciferous-Chazy, Trenton and Cincinnati groups. The labels accompanying the species should indicate. the minor, or local, geological horizon. Practice has also shown the advantage of grouping together all the fossils of each basin or geological province, since in this way only is it possible to indicate clearly the relations which the various provinces bear to one another. Such an arrangement will necessarily cause duplication of certain species, but this is not objectionable, as the forms recurring in two or more provinces illustrate to what extent geographic dispersion has taken place. This method of installation was introduced in the Cretaceous collection of the U. S. National Museum some years ago, by Dr. C. A. White, and has proven practically useful to working paleontologists. It is also in harmony with Sir Henry Howorth's idea that " there should be no attempt made to fill up gaps in one area by inserting evidence from another." *

A stratigraphic collection will also show the introduction in time of the various types of organic beings, and the gradual rise from the ancient and less complex floras and faunas to those of greater complexity characteristic of the more recent geological epochs.

In large museums it is advisable to have distinct and separate paleobotanical, invertebrate and vertebrate collections. Fossil plants and vertebrates are often so large and bulky as to require a method of installation quite different from invertebrate fossils. In small or local museums the various animals of a zone should be kept together, * (Ibidem, p. 323.) 
since it is their province to illustrate the detail of their natural surroundings.

A Synoptic Collection should show the anatomy, embryology, terminology and evolution of every class, together with all the generic steps through which each family has gone in past ages. The first two divisions of the synoptic collection may be illustrated by models and drawings, the terminology by specimens and drawings, colored after the plan so successfully initiated by Bather for the crinoids and Lucas for the vertebrate skull. The genera should be illustrated by typical material of the species on which the genus is based, either by specimens or by figures, or by both, while the labels should give fully the geologic and geographic distribution.

To install the material illustrating the anatomy, embryology and terminology of a class is not difficult, but it is somewhat hard to determine how the generic material shall be shown so as to illustrate the devious paths through which a given class has passed -in order to set forth the course of its evolution. This may be accomplished by grouping the generic tablets of each family in one or more vertical columns. At the base of each is the label giving the name and a short definition of the family characters. The families should be grouped into superfamilies, orders, superorders, and the characters upon which these divisions are based should be clearly set forth on the accompanying descriptive labels. A definition of the class and the known phylogeny should also be displayed in each exhibition case. Plants and vertebrates in the synoptic series, because of their generally large size, must for the most part be illustrated by mounted pictures.

A recent species of all genera having fossil representation should be introduced into these collections, and on each tablet should be given the present specific representation and geographic distribution of the genus.
In the synoptic collections, more than anywhere else, is the need of technical terms necessary for a clear definition of the various divisions illustrated. It is for this reason that each class of organisms in this exhibition series should be accompanied by specimens or drawings colored to attract attention to the part to which the term is applied.

The synoptic collections need not be limited to the illustration of the generic evolution of the classes, but may be advantageously extended to illustrate the evolution of certain specially interesting families, genera, or even species. What series could be more interesting than one illustrating the evolution of the horse or one showing the enormous time dispersal of Lingula and Crania or Pleurotomaria or of Leptœna rhomboidalis and Atrypa reticularis?

The Study Series is not, as a rule, on exhibition, but is stored unmounted in drawers arranged in paper trays. This is the great reserve collection of a museum, and from it the curator derives material for the exhibition series, while the paleontologist or biologist depends upon it for purposes of study. This collection contains no duplicate material for distribution or exchange and must be kept intact. The study collections, since they have no uses other than those just mentioned, should therefore be arranged stratigraphically, this seemingly being the only available method for the administration of so vast an assemblage of fossils. The specimens of each class should, of course, be kept together within each geological group, and this is true also of the floras and faunas of each province. The above treatment of the study collection does not perhaps accord with a strictly biological view, but the needs of the biologist can be provided for by complete card catalogues of all the fossils in the museum.

The Catalogue is the most important agency in the possession of the curator, 
and its management is the highest test of his capabilities. Every species from a single locality, in whatever permanent collection it may be, should be registered upon a separate card giving name, systematic position, terrane, locality, number of specimens, source whence obtained, place of disposition in museum, museum register number, and, if a type published or even a specimen especially referred to in a publication, an exact reference should be given to page and plate. Such cards should be arranged alphabetically, and without regard to any other classification. By the aid of this catalogue, the curator is in the position to know just what material the museum has in stock, and can respond promptly to requests for the loan of material, since the place of any specimen can be ascertained at once. The bulk of the fossil collections being arranged stratigraphically, faunal geologists and paleontologists will be able to secure promptly any desired information without the necessity of referring to the catalogues, while other students of extinct life can refer to any or all the species of a group in the museum by the aid of the catalogues. The cards of this catalogue in use in the U.S. Museum are $4 \frac{1}{2} \times 6 \frac{3}{4}$ inches.

Additional aid can be given the systematic biologist by providing a generic catalogue grouped into classes. Only those genera of which there is material in the museum will have representation in this catalogue. On these cards may also be given the type species and its locality and the place of original description.

The Duplicate collection exists for exchange purposes only, is constantly changing, and requires no attention except in the matter of preservation of identifications.

In Recording the specimens in the U. S. National Museum, each lot of fossils is given a general accession number as soon as received, and later, when the material has been studied, each species from a single locality is given a permanent 'museum register number.' The latter, when practicable, is written upon each specimen, and opposite this number in the record book is entered the name, locality, date and any remarks pertinent to its history. To fossils brought together by the U. S. Geological Survey are attached small, round, green or yellow tickets, upon which are written numbers referring to the 'locality book.' This method is preliminary to permanent record. Either system permits the assembling in one tray for study, all the material of a species from many localities, without danger of confusing their history. "Specimens can be named at any time, but the locality once lost, the object becomes comparatively valueless. The record of donors should be accurate and complete so that the specimens from any given source can be traced at once to their location." *

Types and illustrated specimens should have in addition to the museum register number, some conspicuous mark to call attention to their great scientific value, and to guard against loss. In the U. S. National Museum a small, green, diamondshaped ticket is pasted on each specimen; this being a method long in use by Prof. James Hall. Charles Schuchert.

U. S. National MUSEum, WASHINGTON, D. C.

\section{THE FLOW OF THE CONNECTICUT RIVER. $\dagger$}

THERE is a general and doubtless wellfounded belief that the cutting of the forests is injurious to the flow of the streams whose basins are thus denuded. This belief is based upon the common experience of men long familiar with the streams in question, and is also supported by theory. Few opportunities, however, exist for definitely measuring the effect that is produced, for the reason that upon very few streams have

* Goode. (loc. cit., p. 58.)

† Read before the American Forestry Associatico, 1895. 